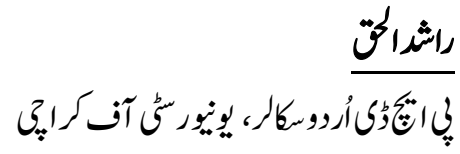

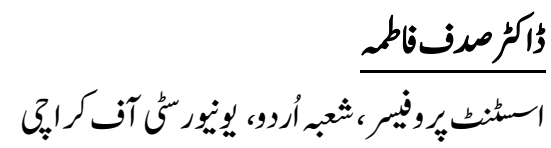

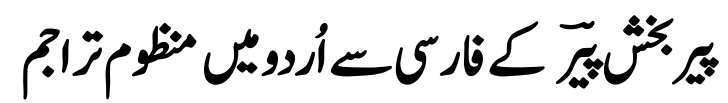

Rashid ul Haq

Ph.D Urdu Research Scholar, University of Karachi.

Dr. Sadaf Fatima

Assistant Professor, Department of Urdu, University of Karachi.

\title{
Versified Translations of Persian into Urdu by Peer
}

\section{Bakhsh Peer}

There is a tradition of versified translations of Urdu literature. This can be particularly seen in both poetic and prose works of Sheikh Saadi. These literary works have been translated a number of times but no serious effort has been done so far to make a versified translation. Gobind Parshad has done translation of Bostaan Saadi with the title of 'Bostaan Mutarjim'. Peer Bakhsh Peer believes that he has not only done versified translations of Kareema, Bostaan and Gulistaan but also stories 'Mukhtalifa' (Gulzaar e Dabistaan). In this article, versified translation of Peer Bakhsh Peer has been treated as a subject matter. There is no doubt at the fact that versified translations of Peer Bakhsh Peer will be considered an important milestone. Peer Bakhsh Peer has not only done versified translations of Sheikh Saadi but he has also done translation of first edition of 'Masnavi' of Maulana Rome. All of these translations are an important addition to versified Urdu literature.

Keywords: Peer Baßhsh Peer, Versified Translations, Bostaan Saadi Kareema, Gulistaan, Sheißh Saadi, Manzuun-Kalaam, Dera Ghazi Khan, Rasoolpur. 


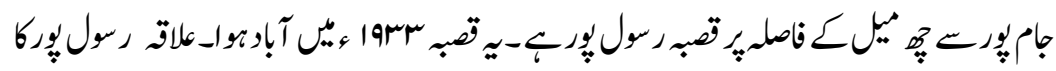

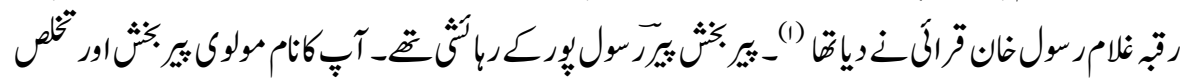

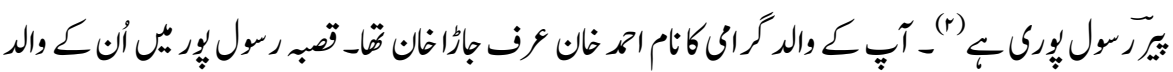

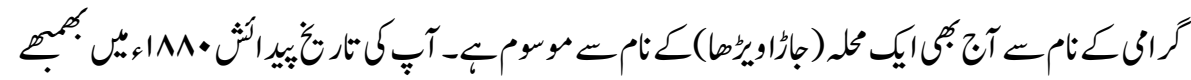

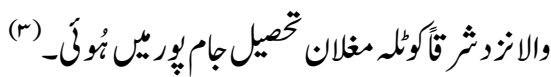

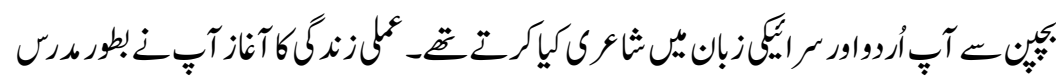

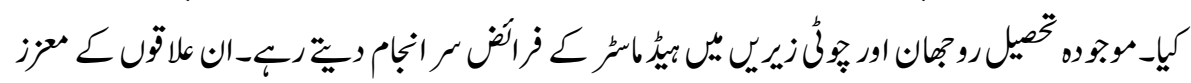

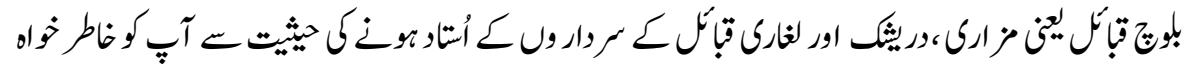

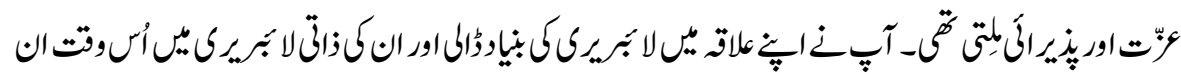

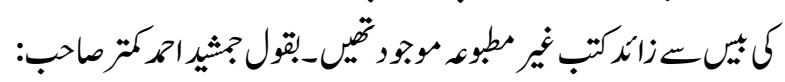

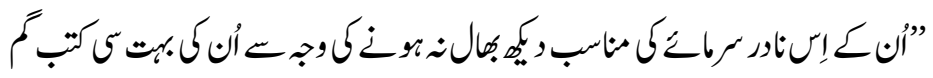

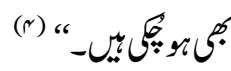

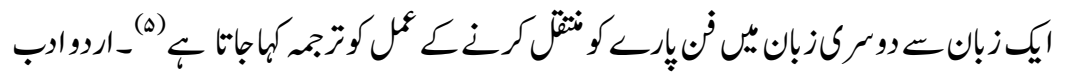

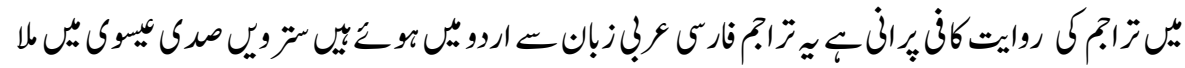

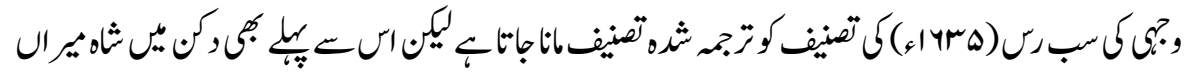

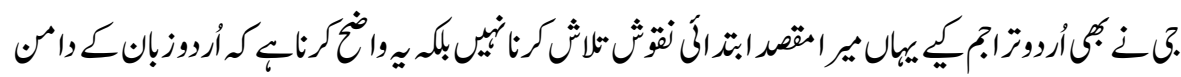

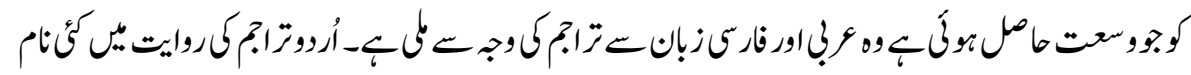

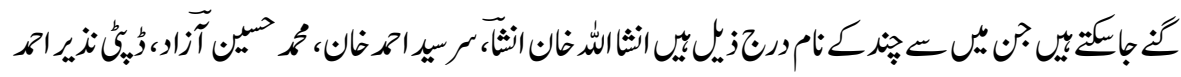

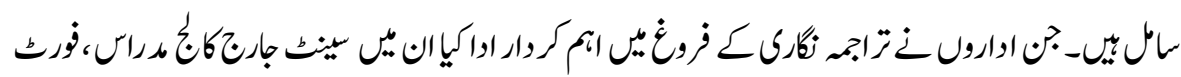

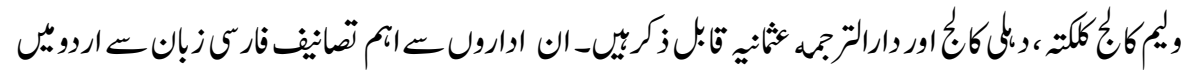

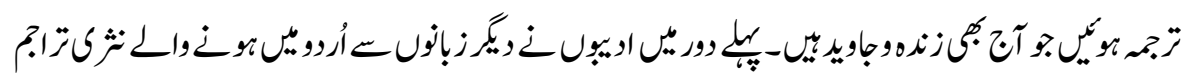

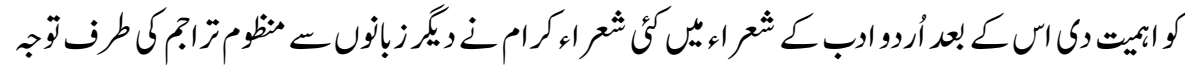

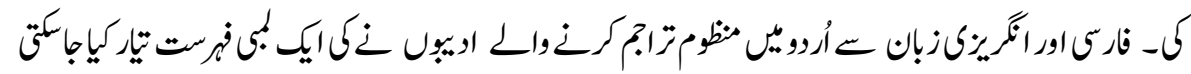




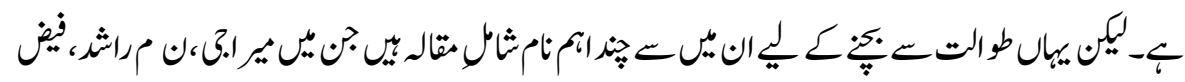

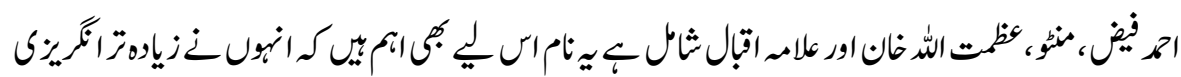

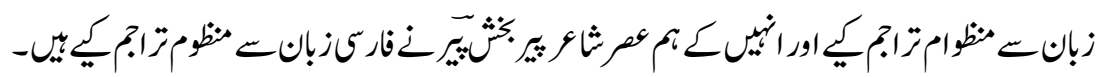

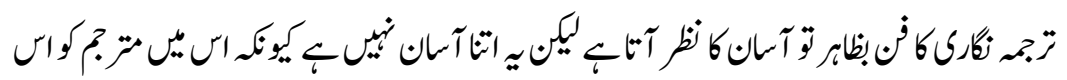

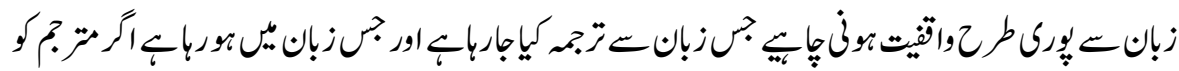

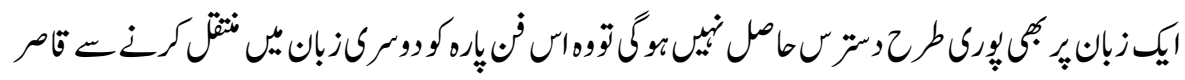

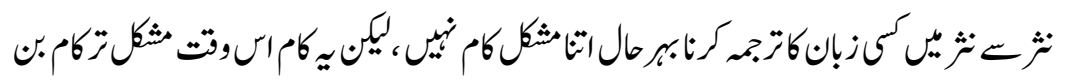

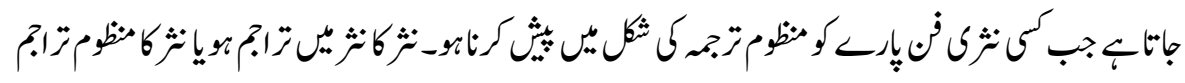

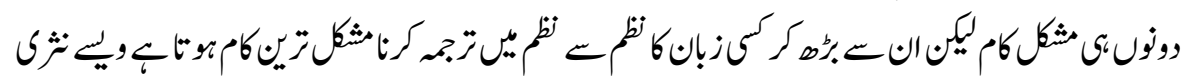

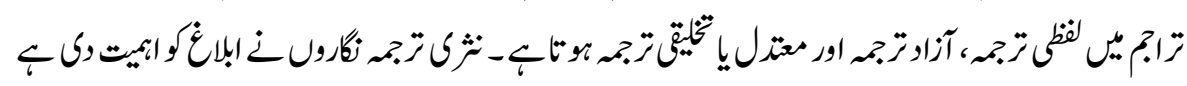

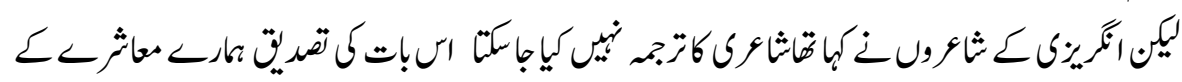

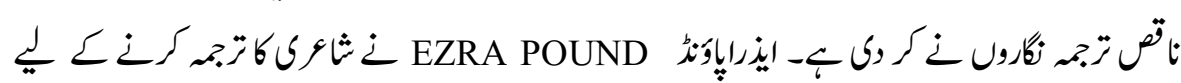

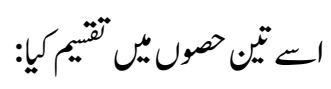

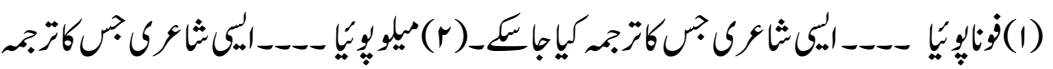

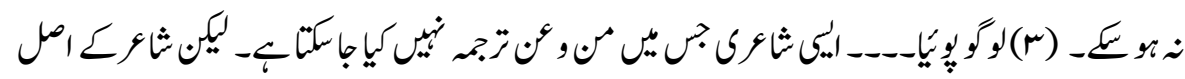

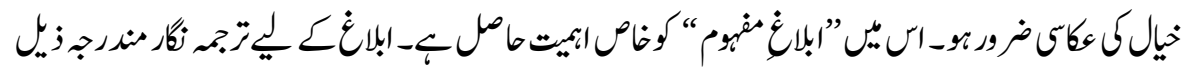

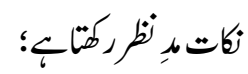

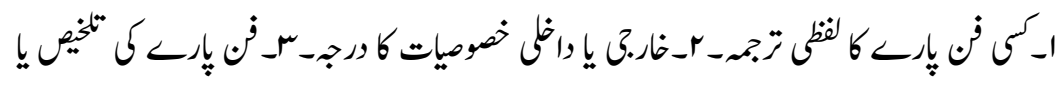

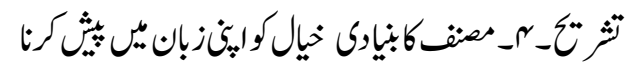

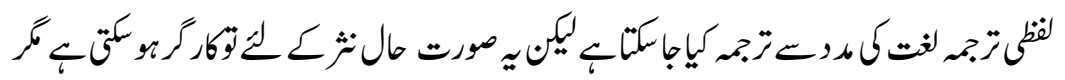

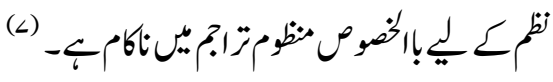




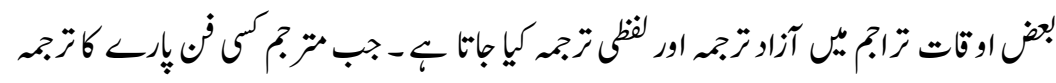

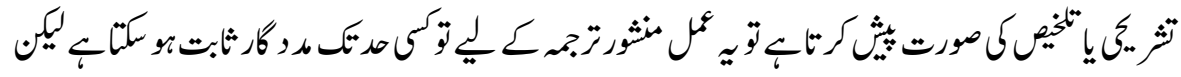

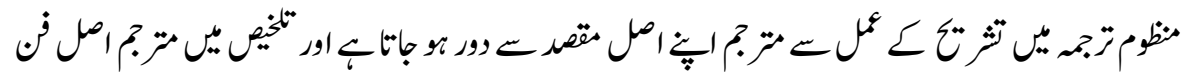

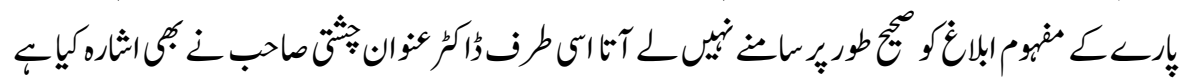

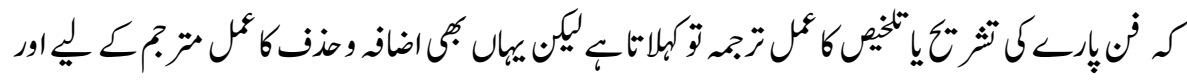

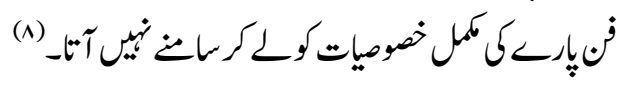

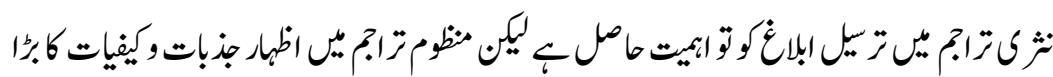

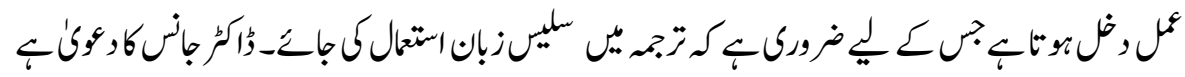

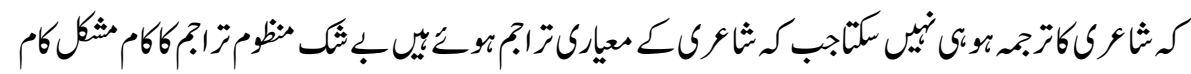

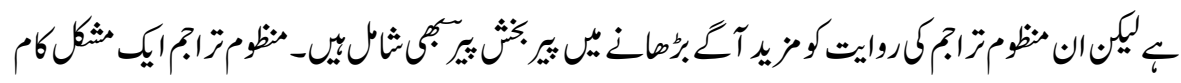

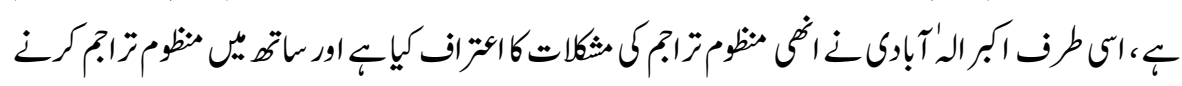

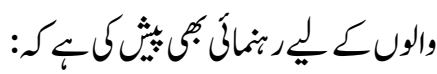

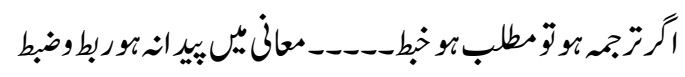

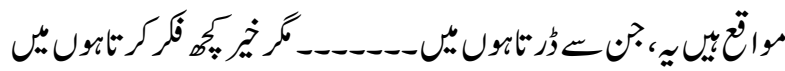

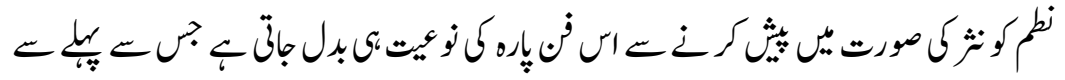

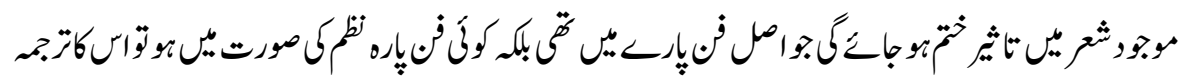

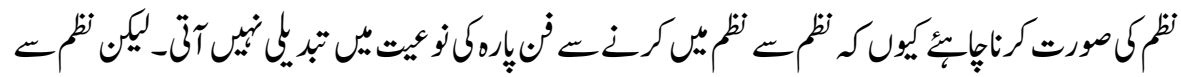

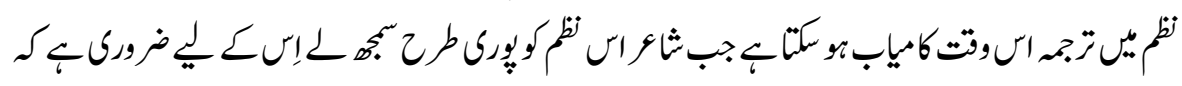

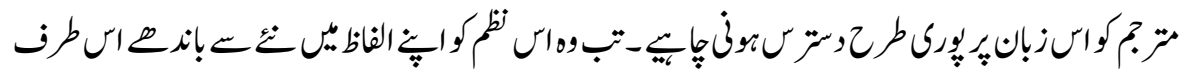

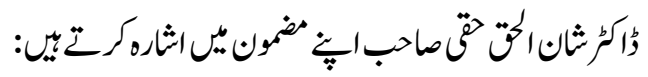

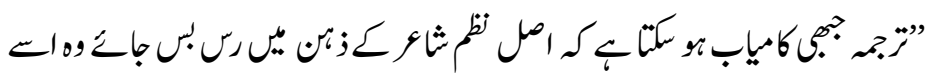

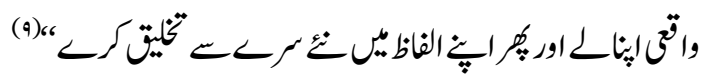


ISSN (Print): 2709-9636 | ISSN (Online): 2709-9644

Volume 2, Issue IV, (October to Decmber 2021)

كانّ

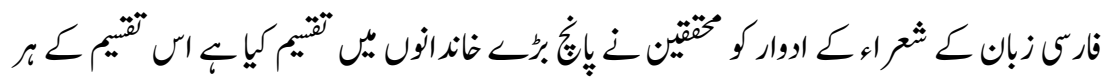

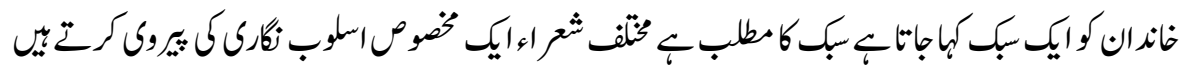

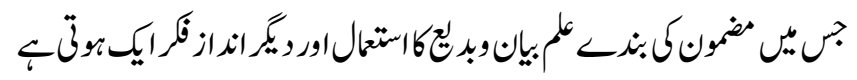

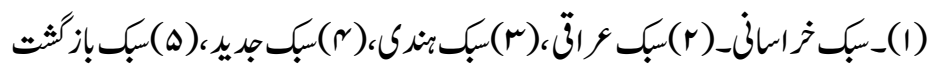

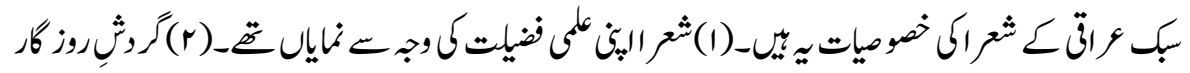

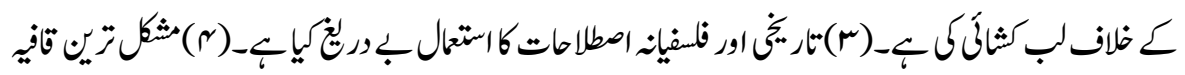

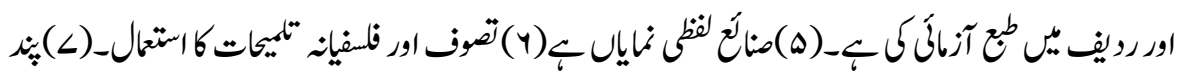

ك ع كنايثن

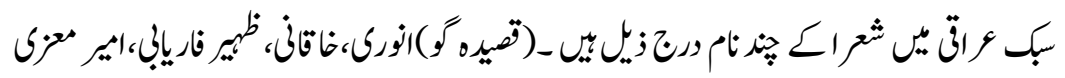

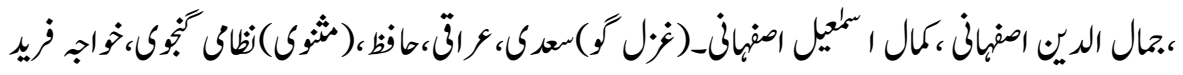

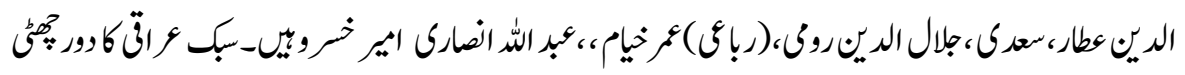

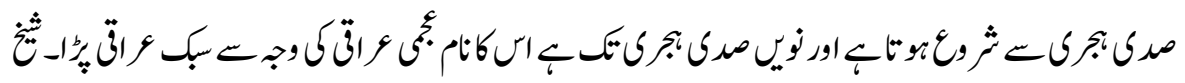

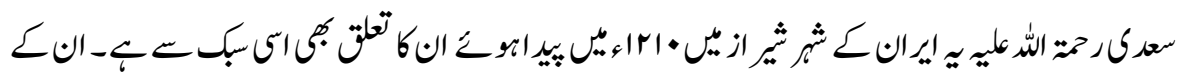

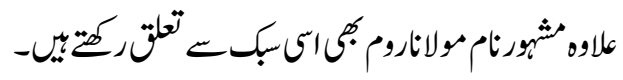

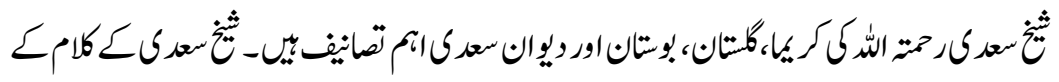

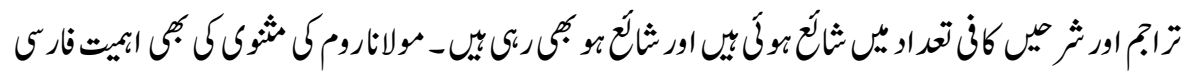

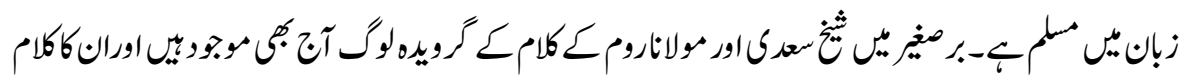

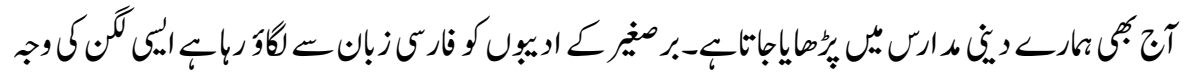

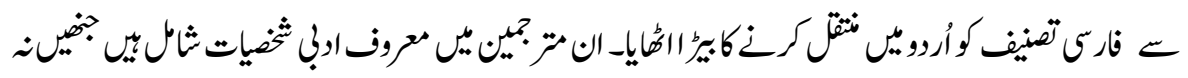

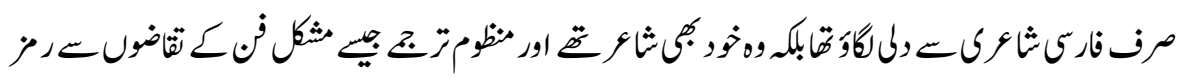

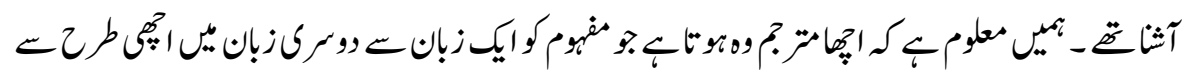

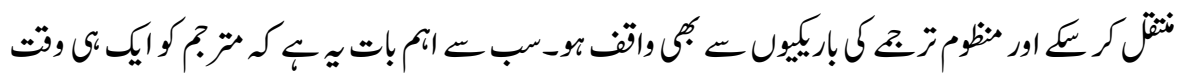

ras 


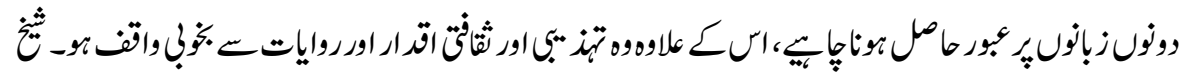

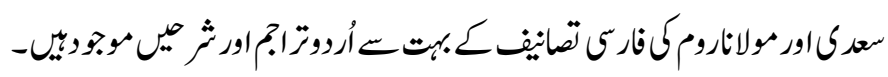
كوبنز

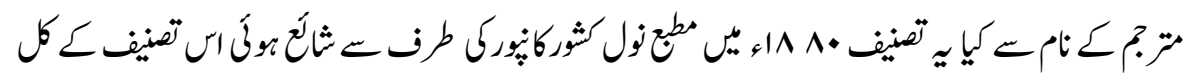

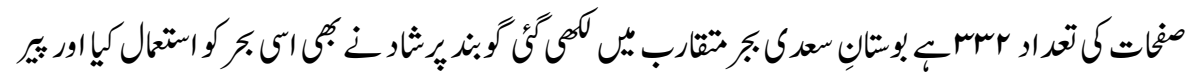

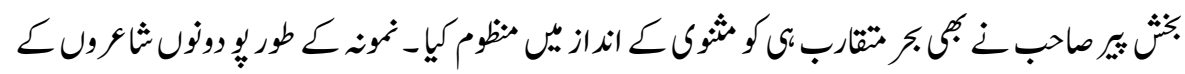

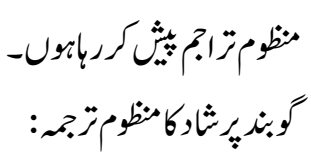

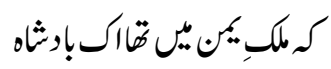

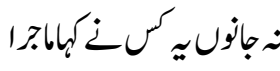

(1.0)

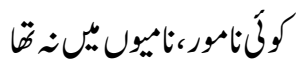

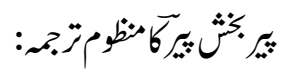

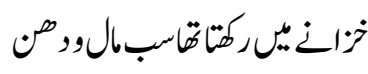
(10848)

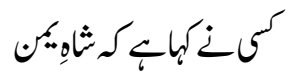

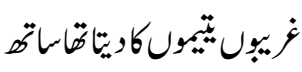

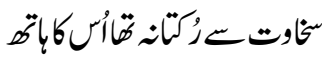

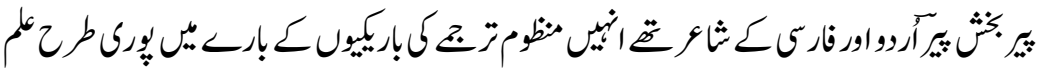

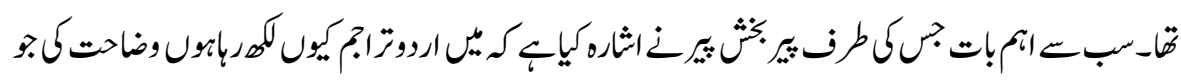

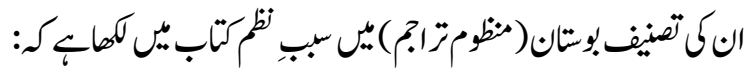

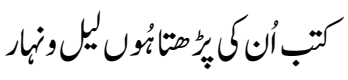

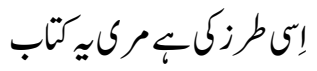

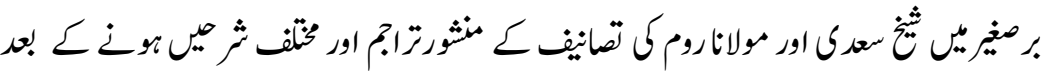

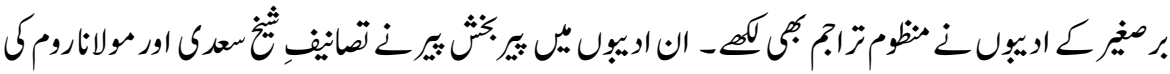




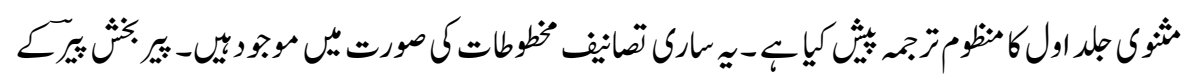

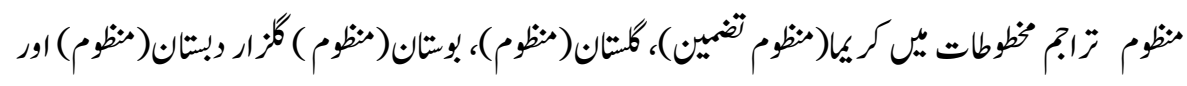

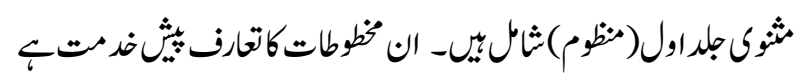

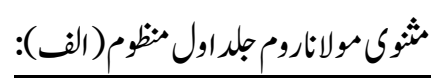

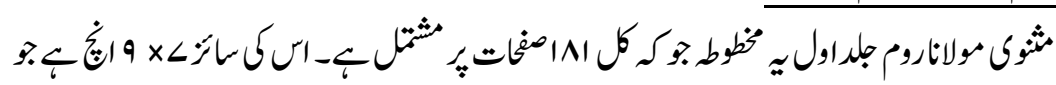

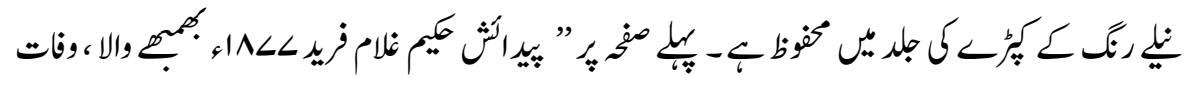

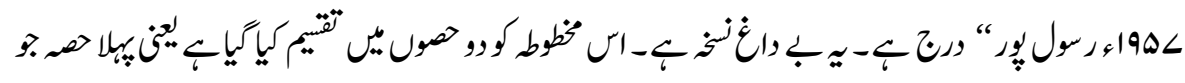

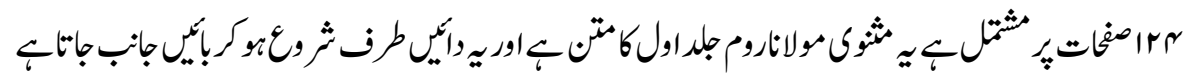

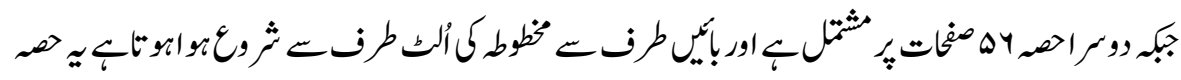

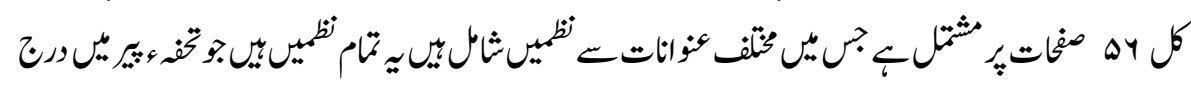

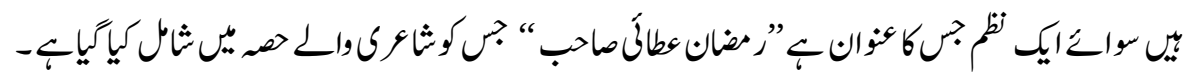

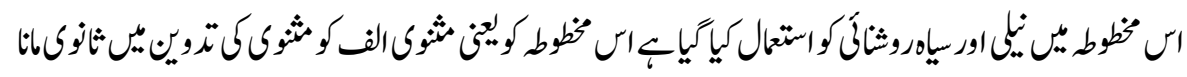

مثونمولانارومجداولمنظم(ب):

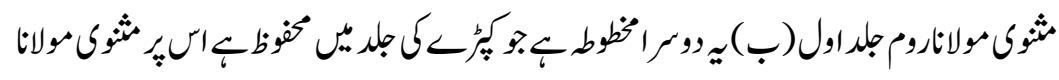

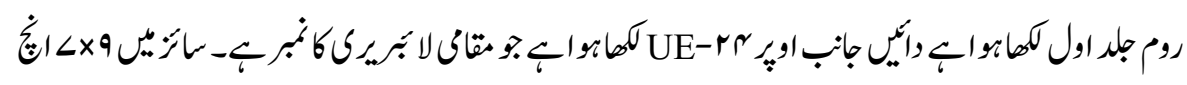

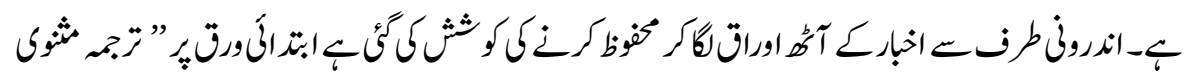

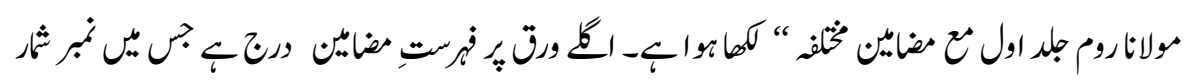

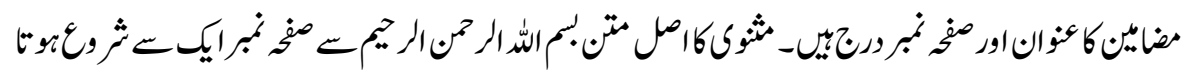

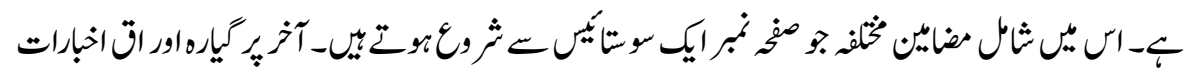

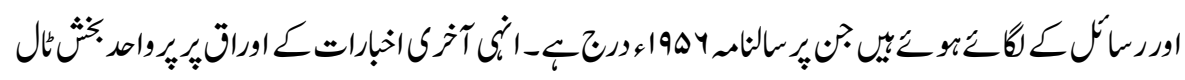

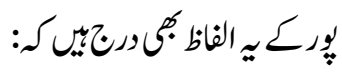




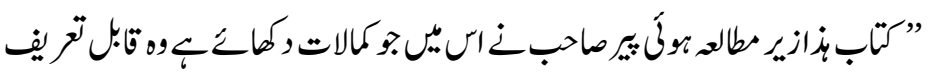

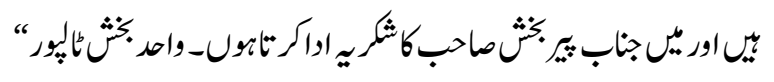

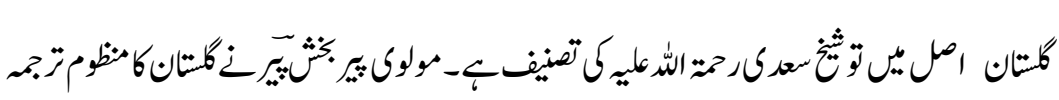
:

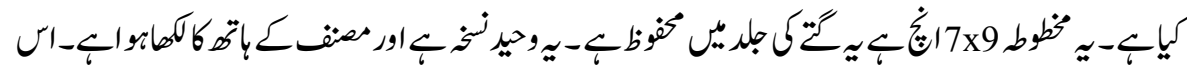

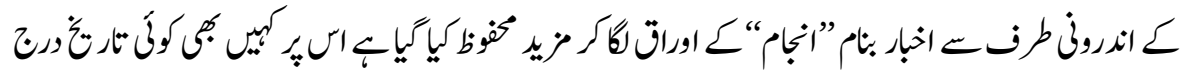

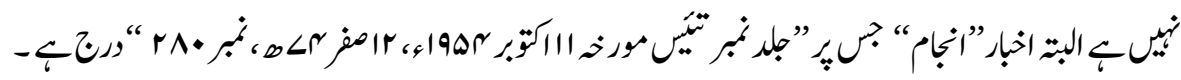

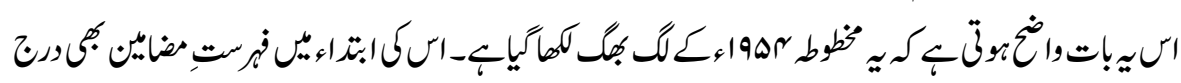

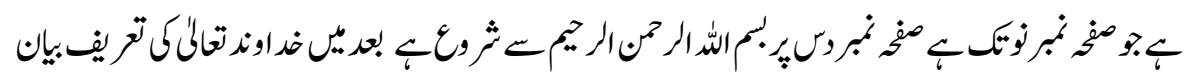

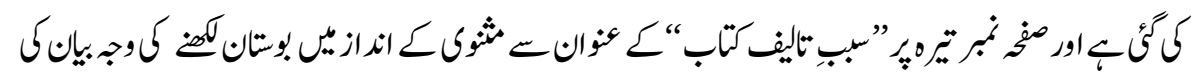

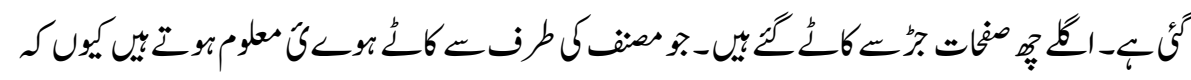

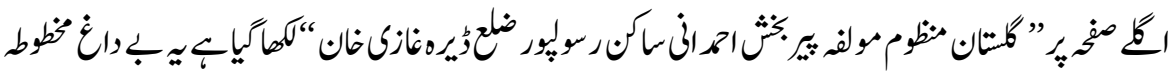

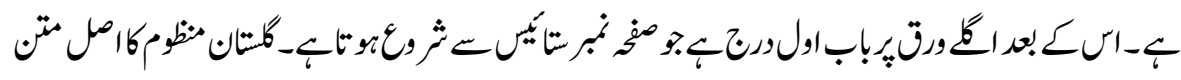

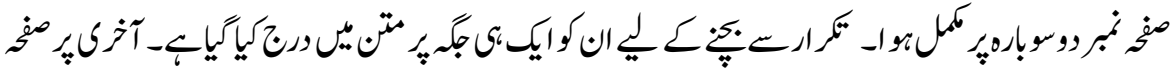

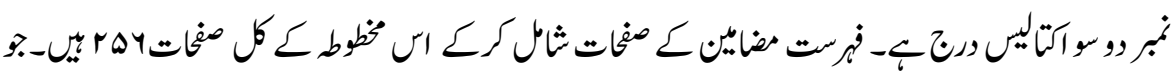

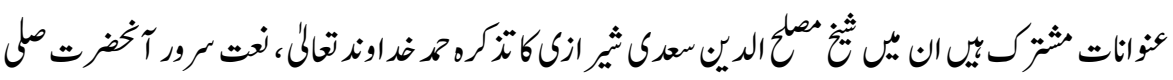

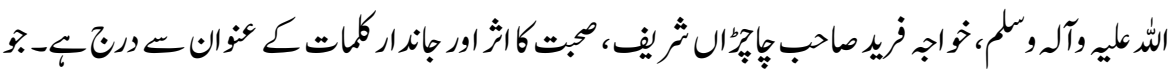

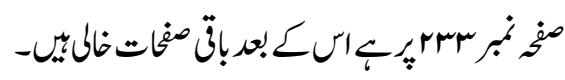

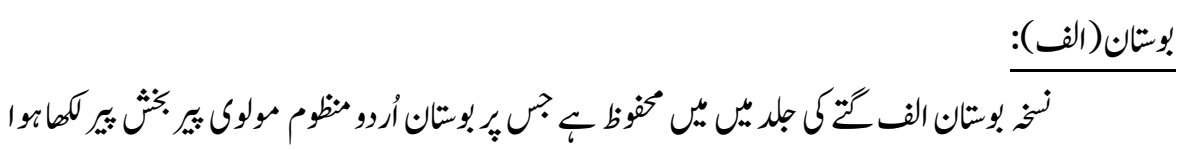

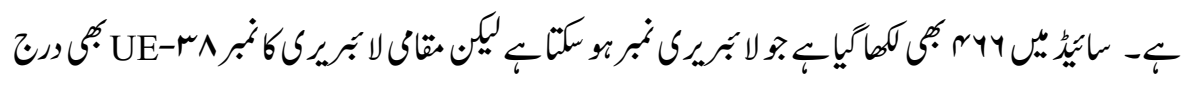

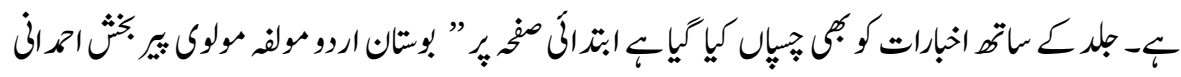

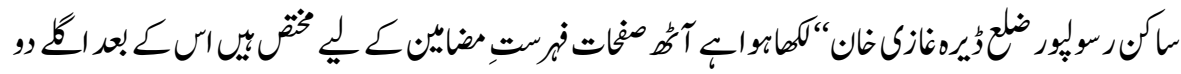




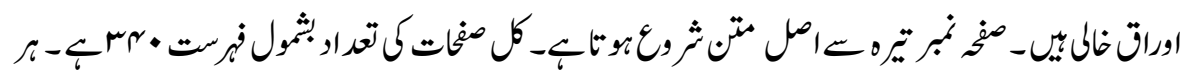

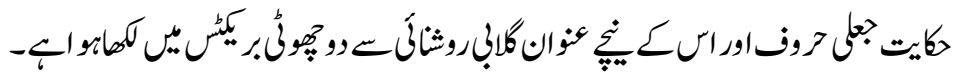

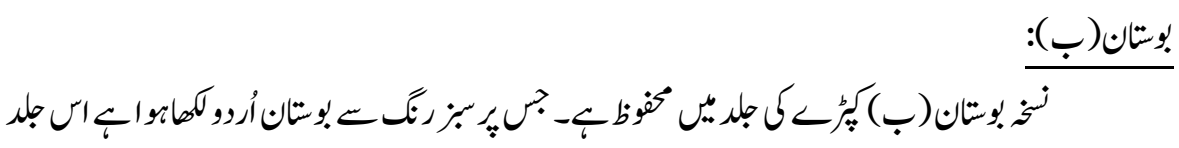

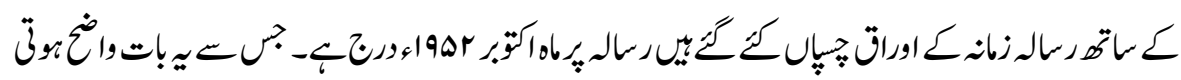

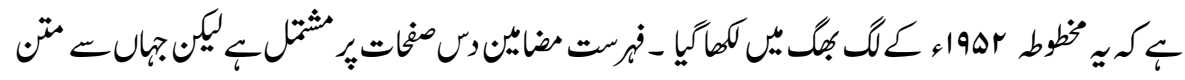

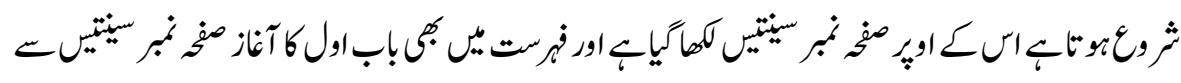

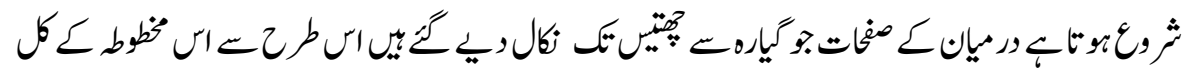

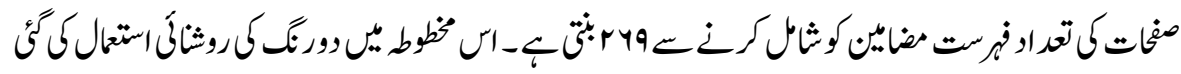

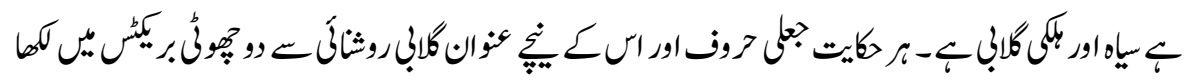

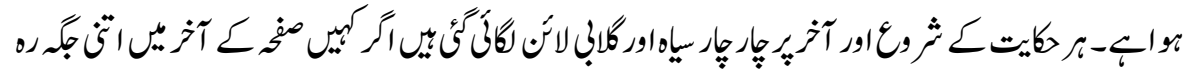

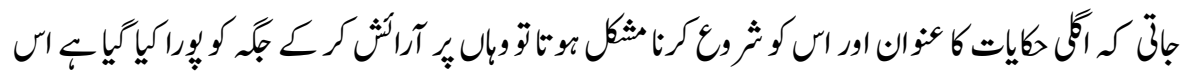

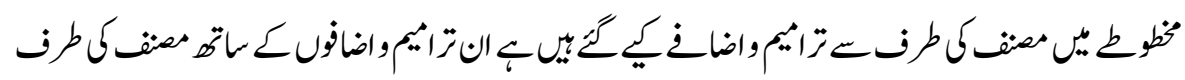

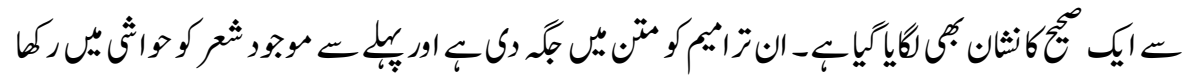

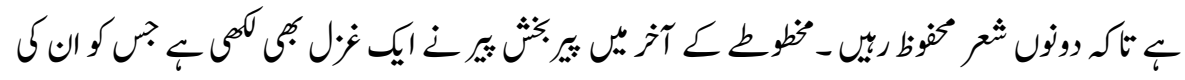

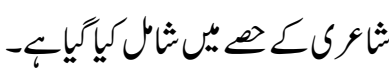

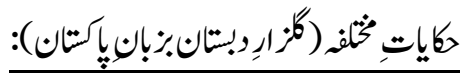

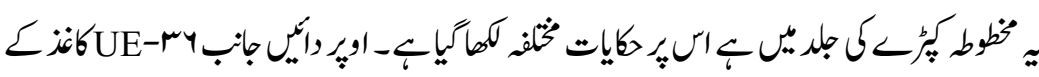

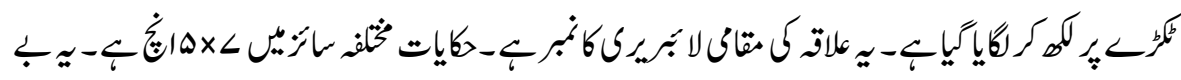

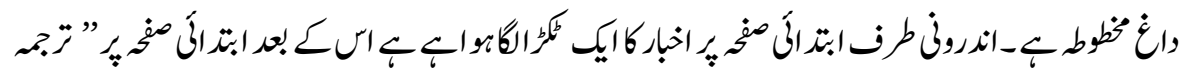

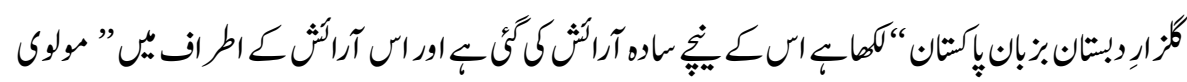

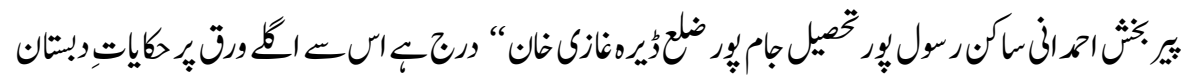

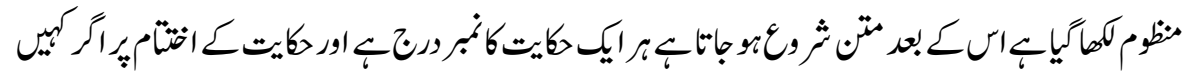




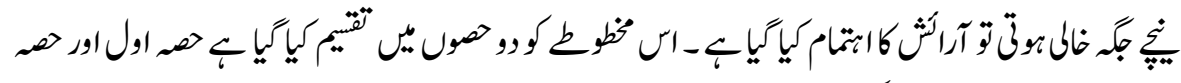

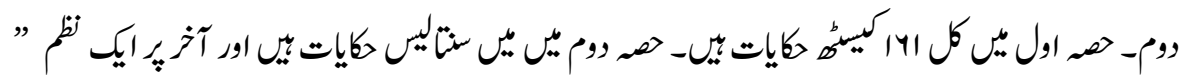

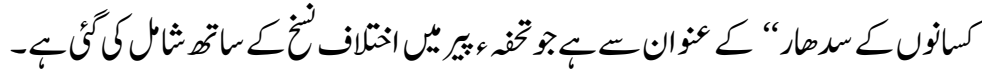

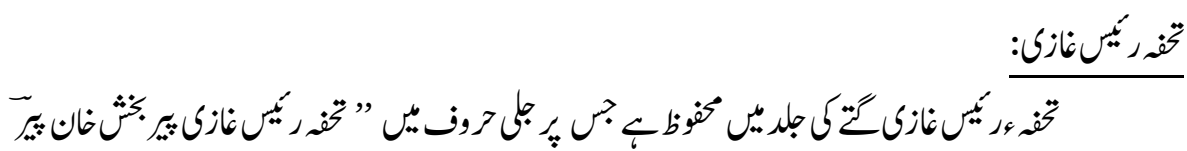

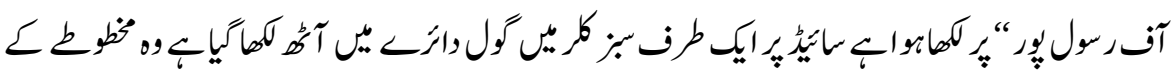

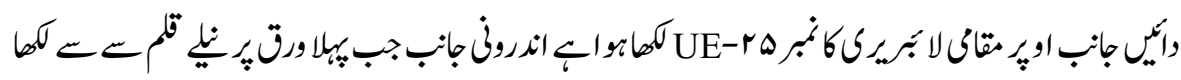

$$
\text { : }
$$

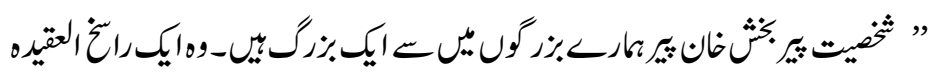

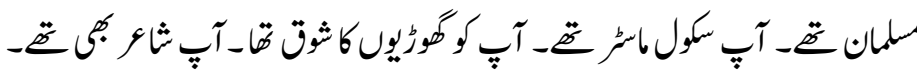

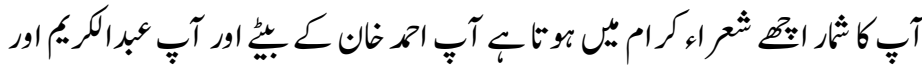

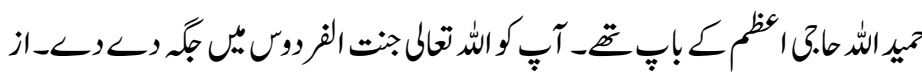

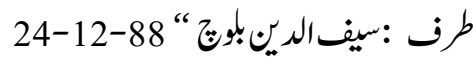

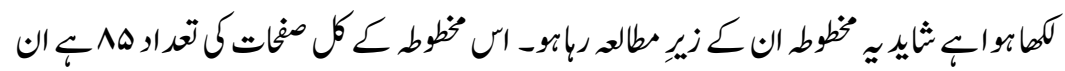

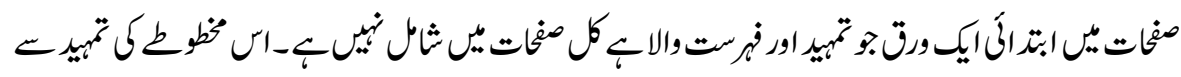

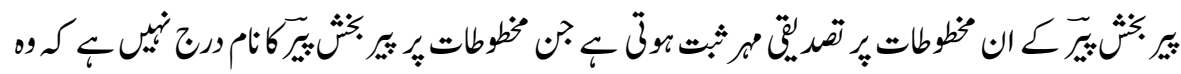

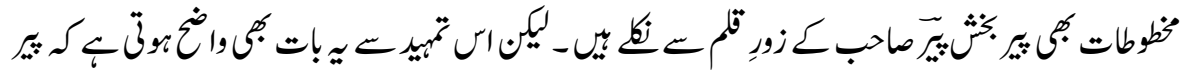

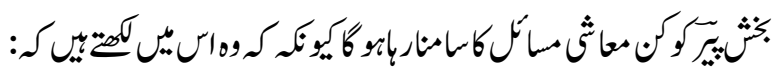

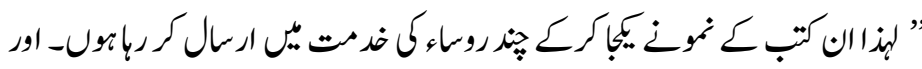

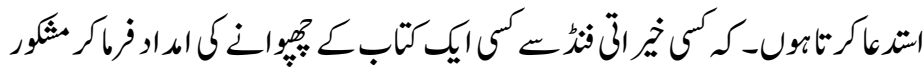

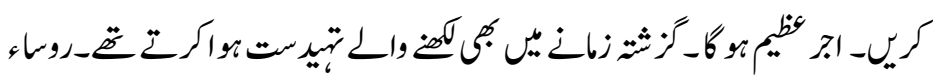

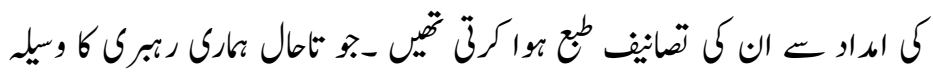




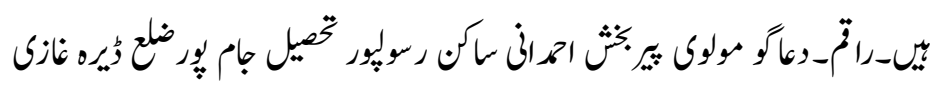
"نان

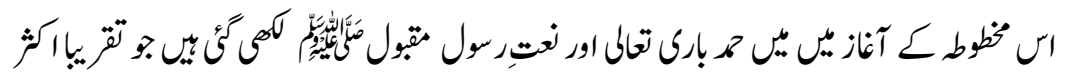

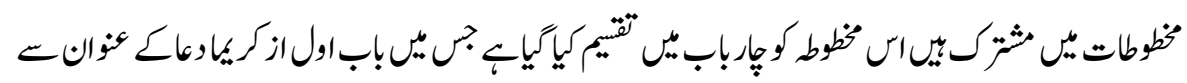

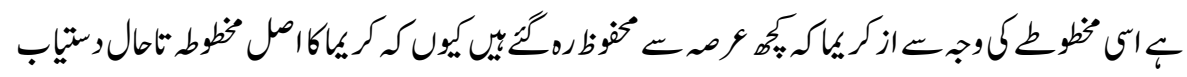

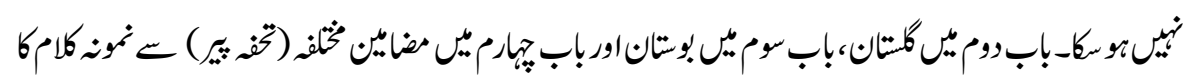

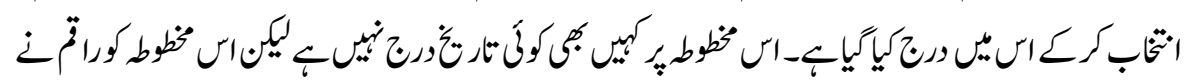

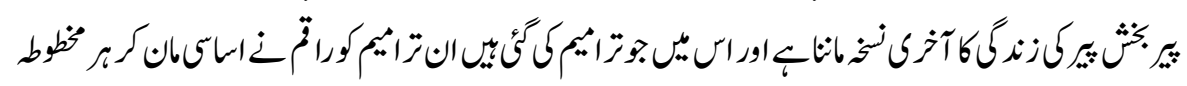

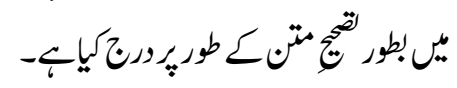

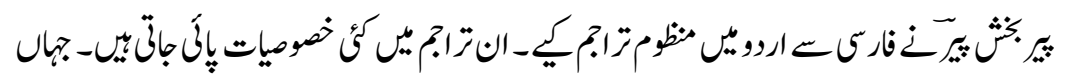

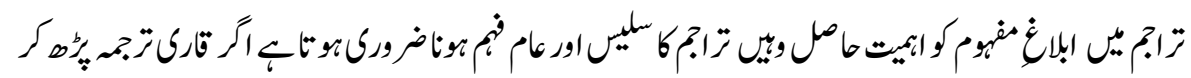

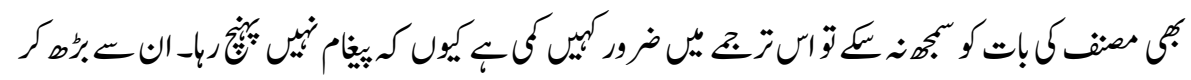

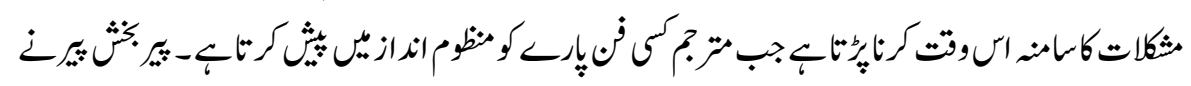

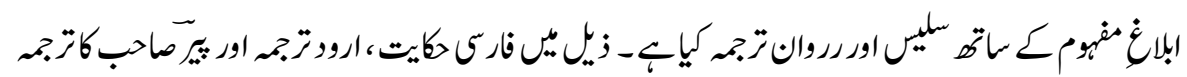

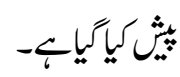
$:=6$

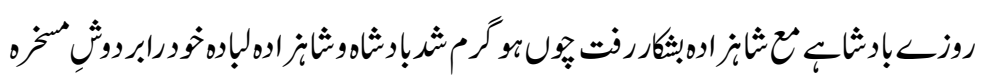

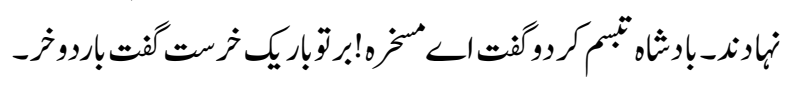

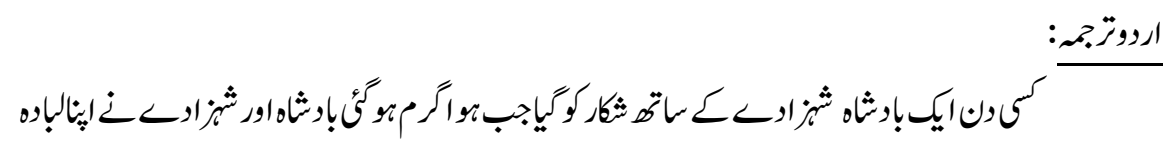

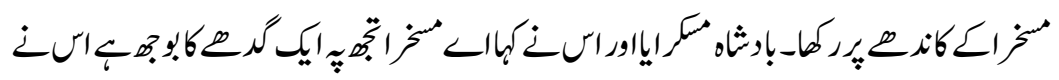
كما ووكر 


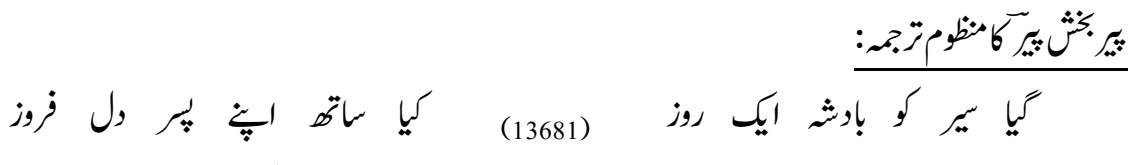

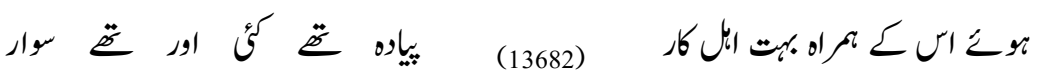

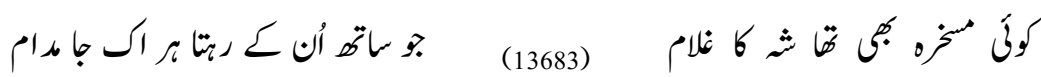

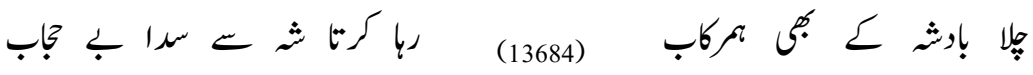

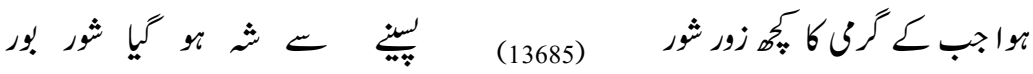

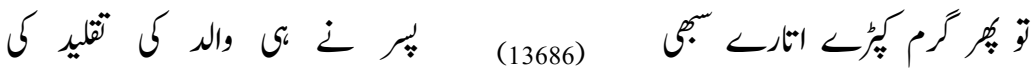

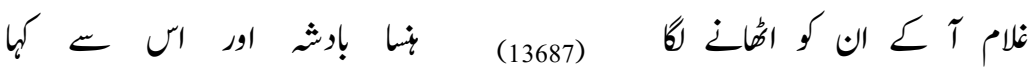

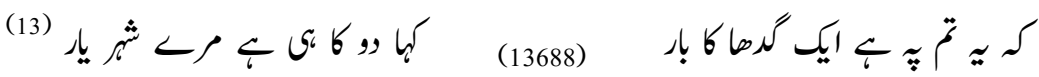

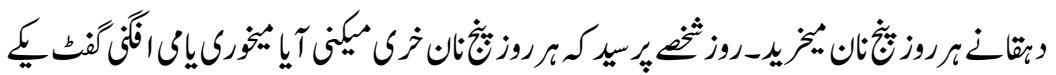

$$
\text { : }
$$

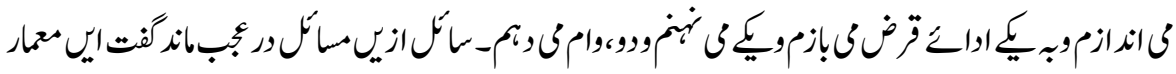

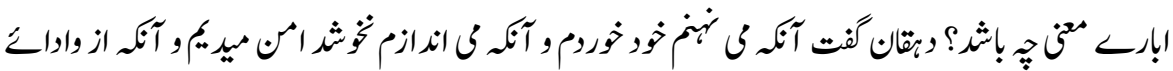

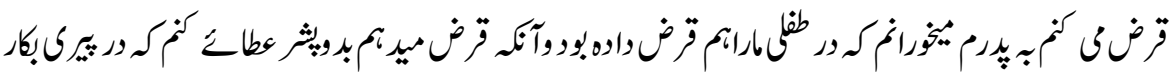

$$
\text { نوايرآها }
$$

اروتزبمد:

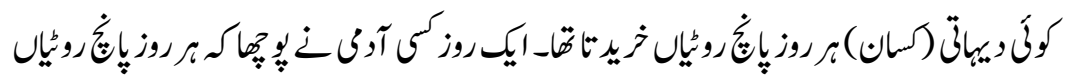

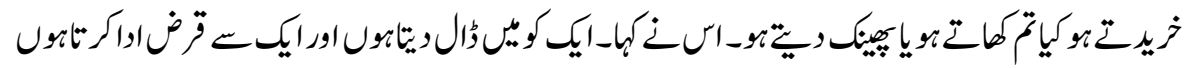

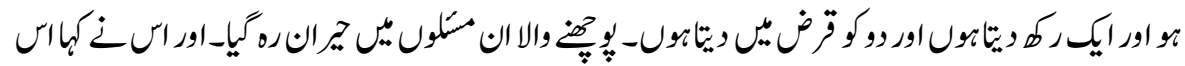

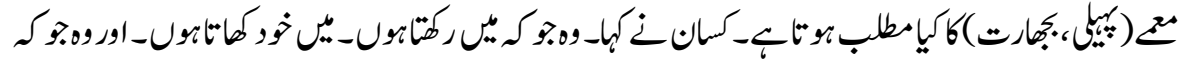

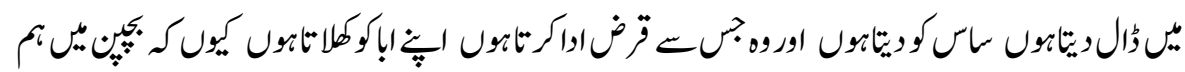

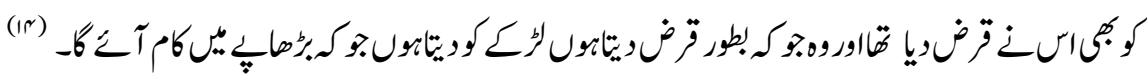


مثومتجم

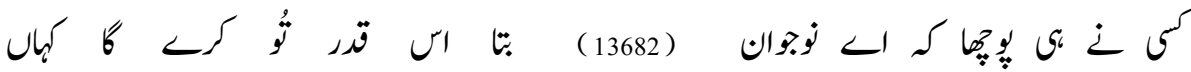

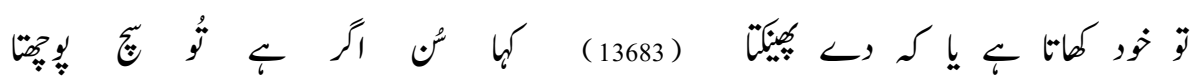

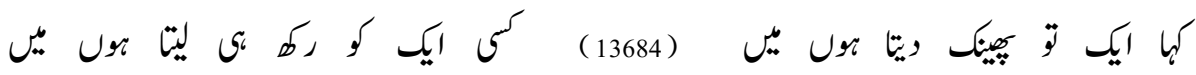

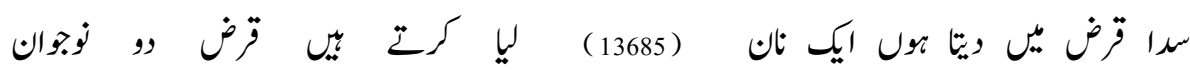

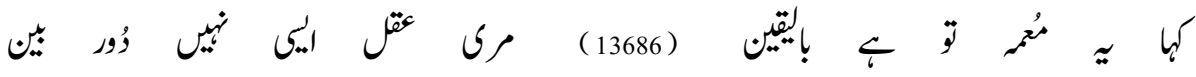

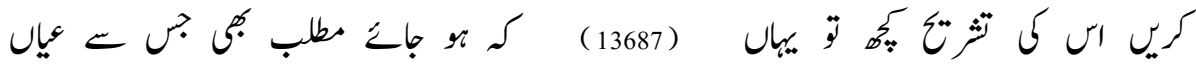

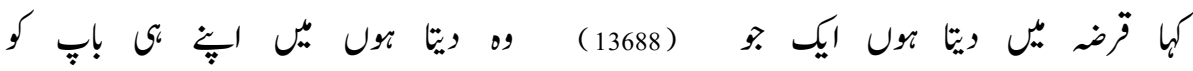

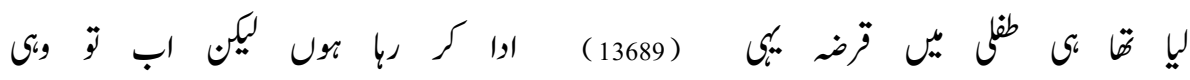

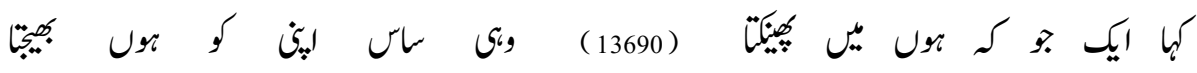

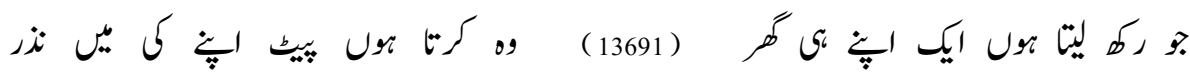

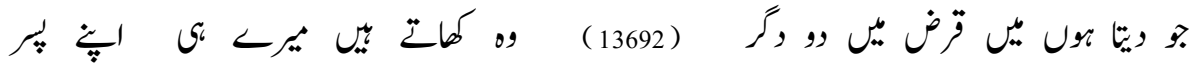

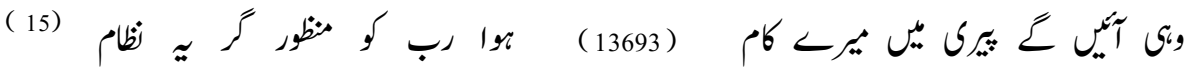

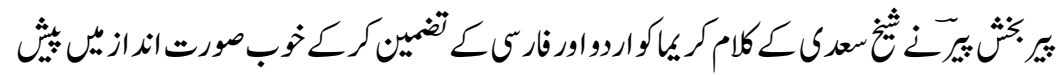

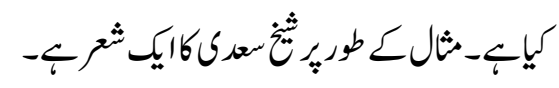

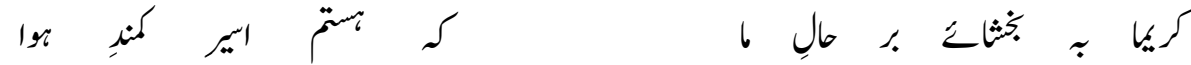

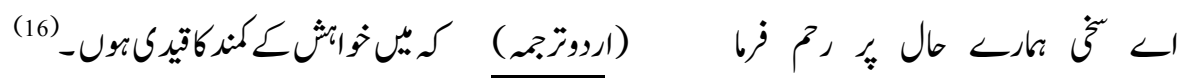

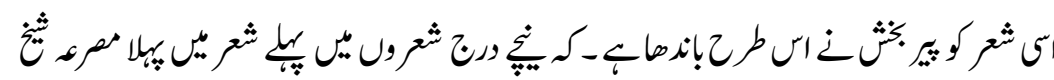

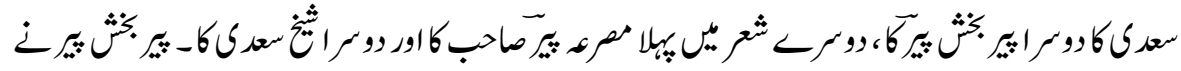

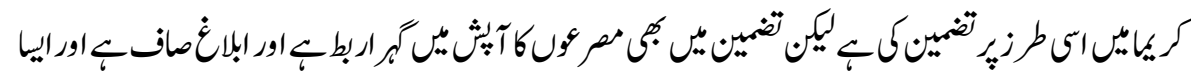

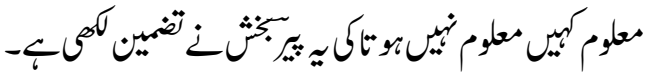




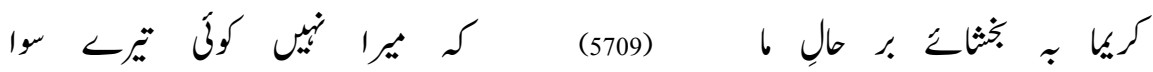

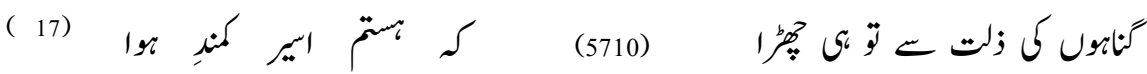

$$
\begin{aligned}
& \text { روبركثنل: }
\end{aligned}
$$

ورِنَبم:

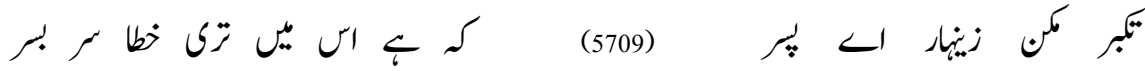

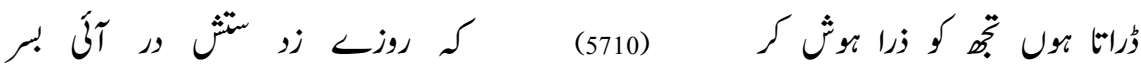

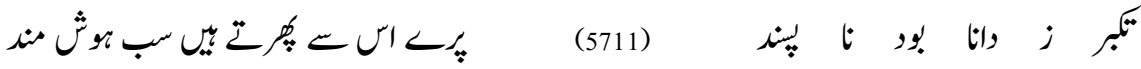

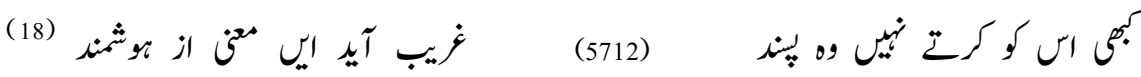

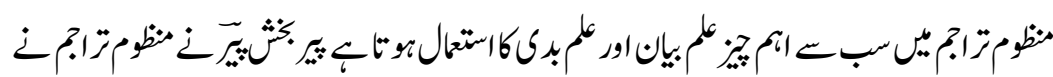

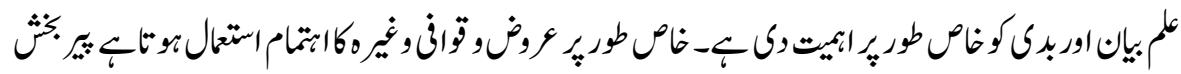

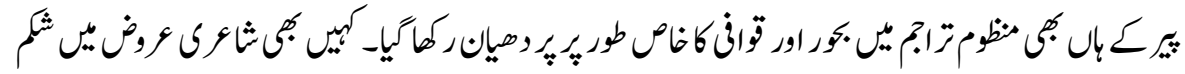

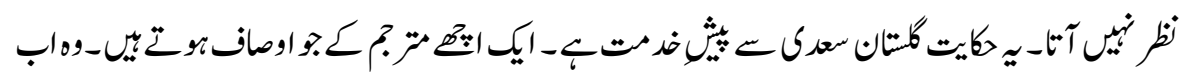

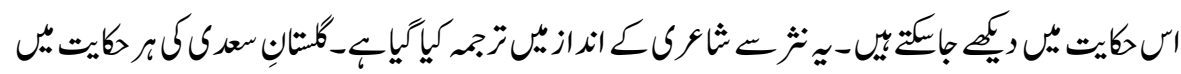

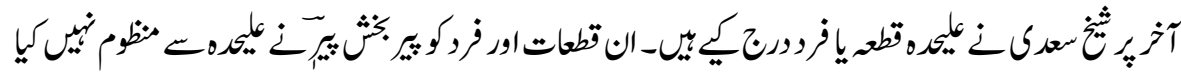

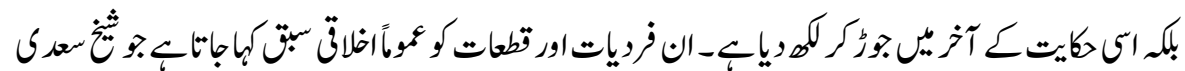

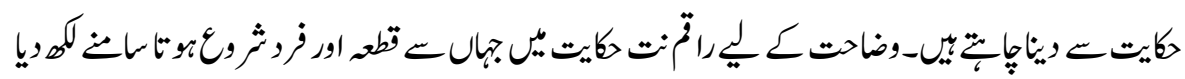

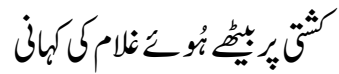

$$
\begin{aligned}
& \text { (L) (L) }
\end{aligned}
$$

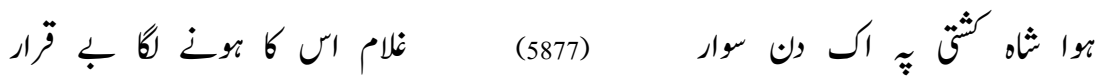

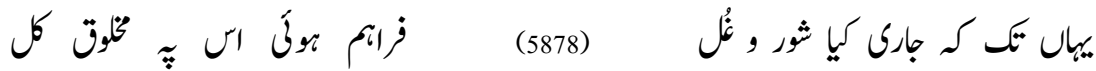

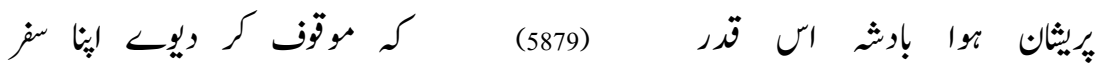

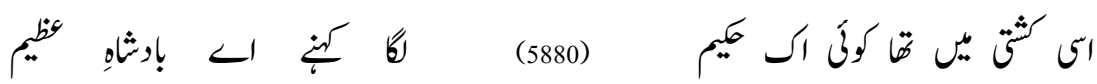

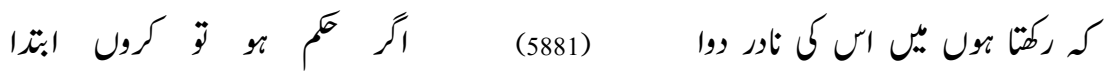




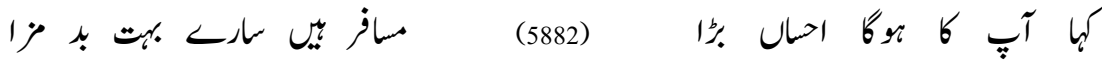

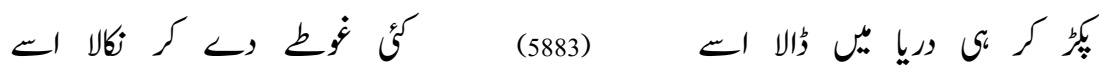

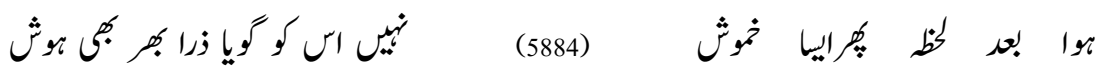

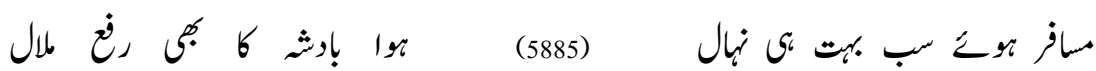

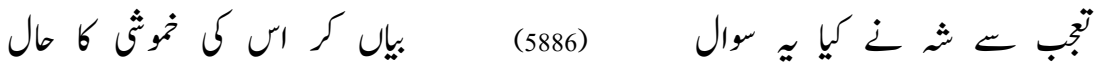

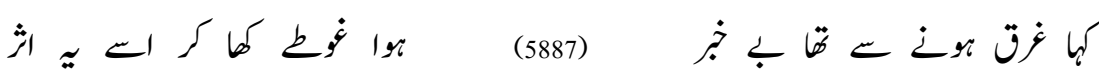

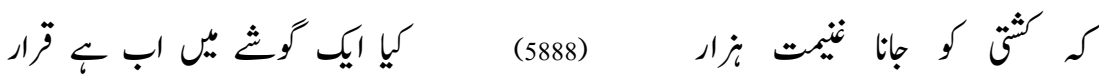

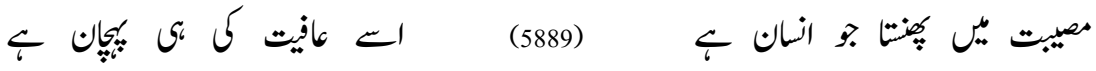

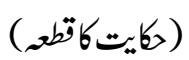

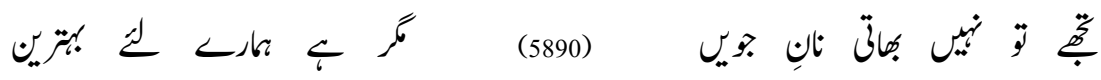

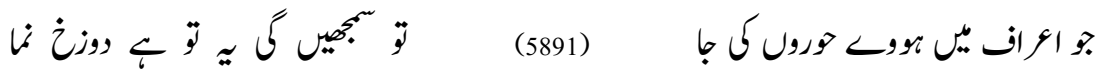

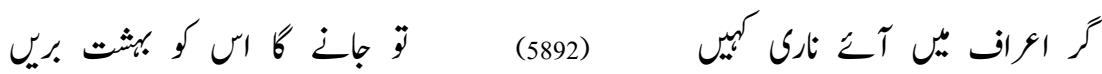

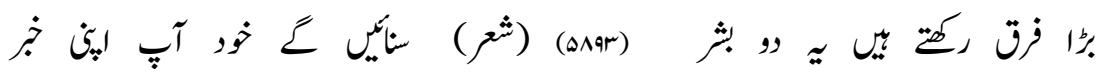

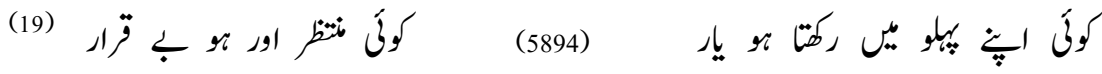

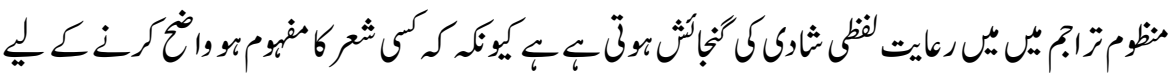

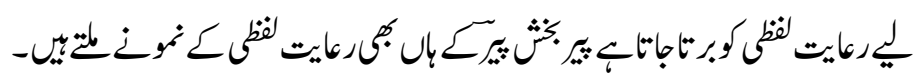

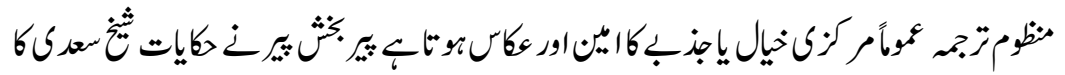

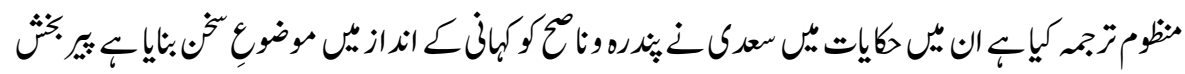

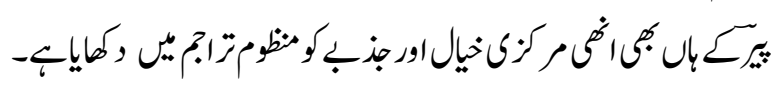

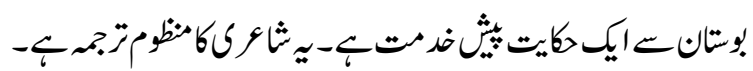

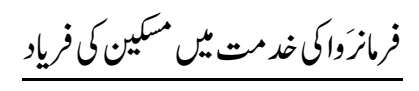$$
\text { كيت: }
$$

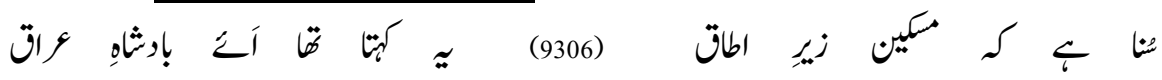

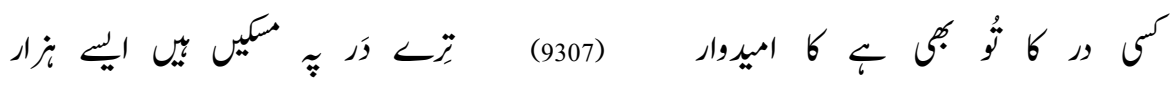




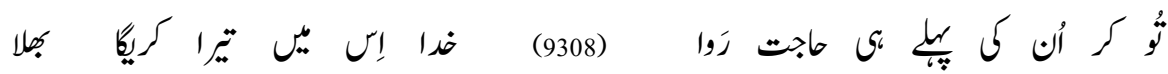

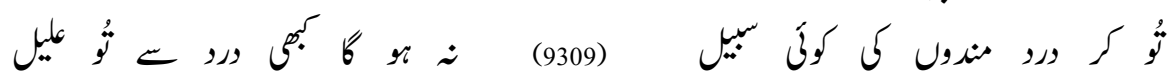

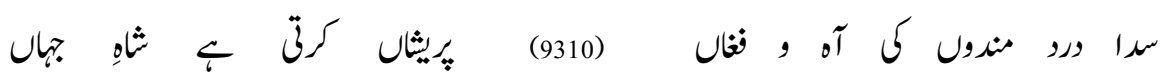

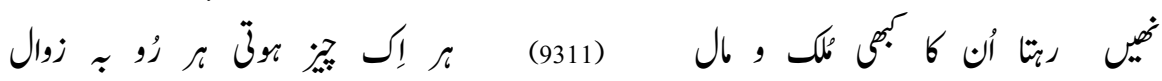

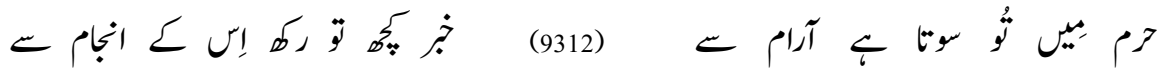

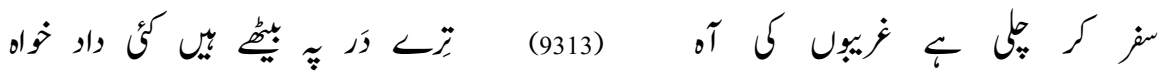

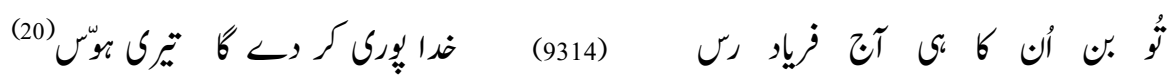

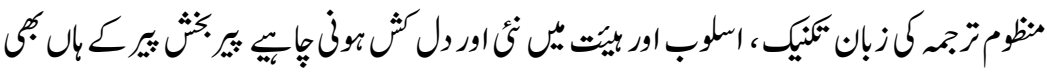

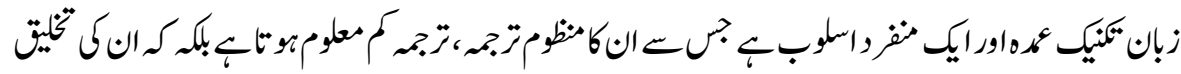

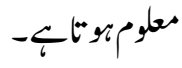

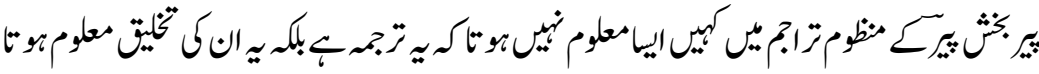

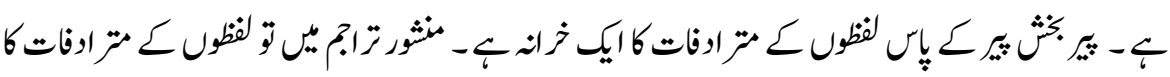

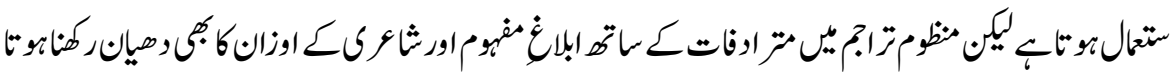

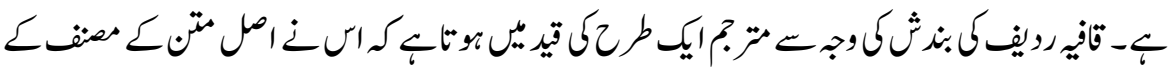

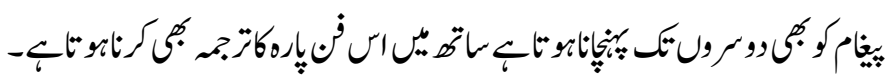

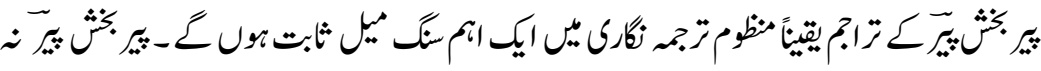

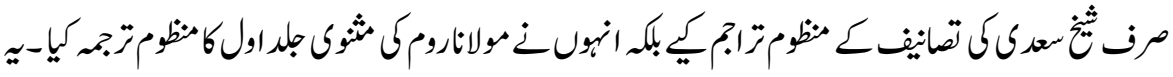

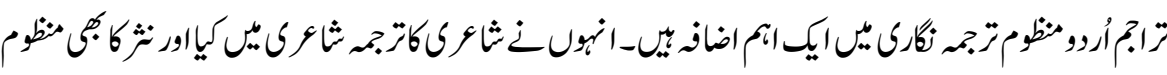

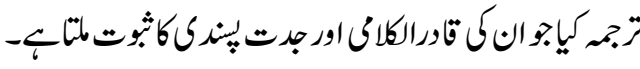
و توالدجات

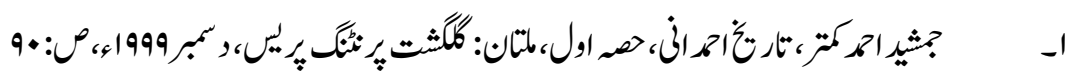
r 


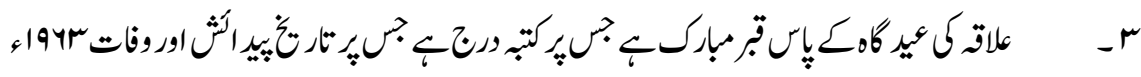

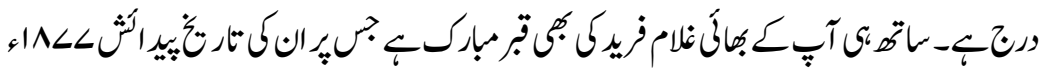

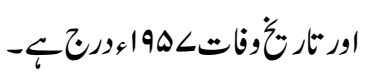

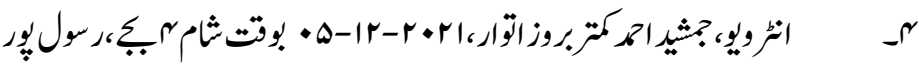

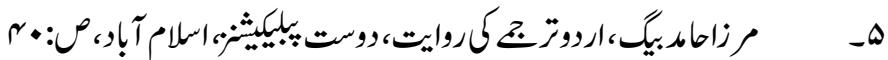

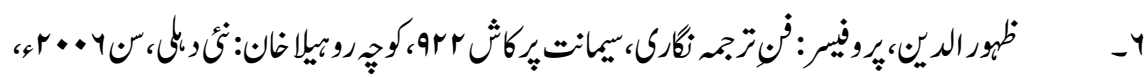
ص:m

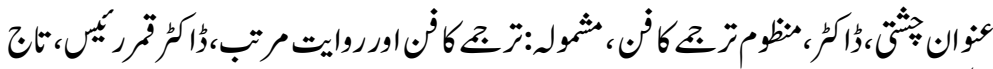

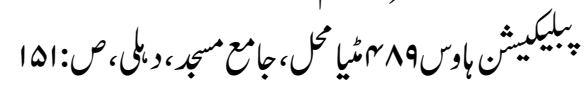

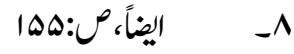

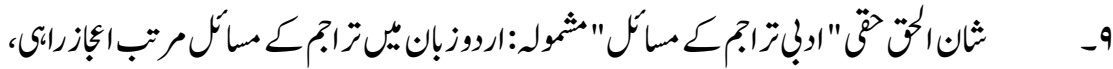

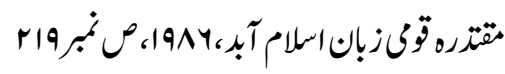

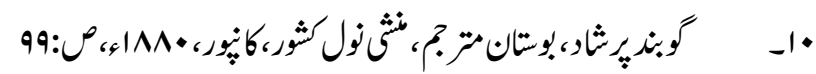

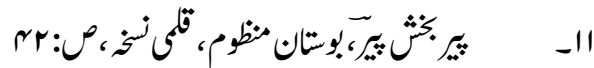

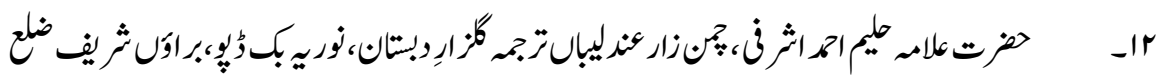

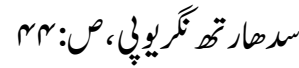

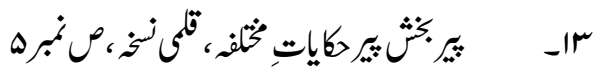

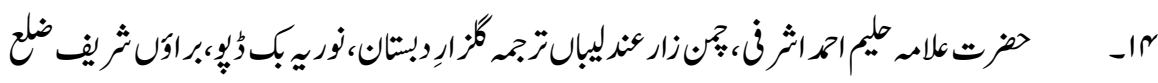

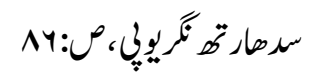
10

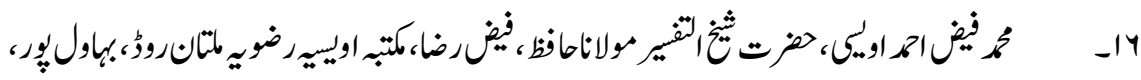
$r: 0$ 
ISSN (Print): 2709-9636 | ISSN (Online): 2709-9644

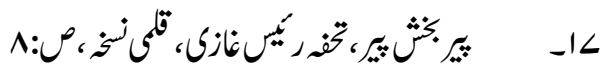

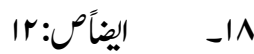

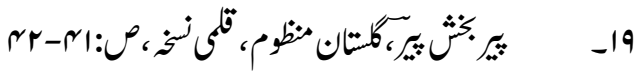

$$
\begin{aligned}
& \text { r. }
\end{aligned}
$$

